\title{
Developmental programming of the HPA axis and related behaviours: epigenetic mechanisms
}

\author{
Stephen G Matthews ${ }^{1,2,3}$ and Patrick O McGowan'1,4,5 \\ 1Department of Physiology, University of Toronto, Toronto, Ontario, Canada \\ 2Departments of Obstetrics \& Gynaecology and Medicine, University of Toronto, Toronto, Ontario, Canada \\ ${ }^{3}$ Lunenfeld Tanenbaum Research Institute, Sinai Health System, Toronto, Ontario, Canada \\ ${ }^{4}$ Department of Biological Sciences and Center for Environmental Epigenetics and Development, University of Toronto, Scarborough, Ontario, Canada \\ 5Department of Cell and Systems Biology, Department of Psychology, University of Toronto, Toronto, Ontario, Canada
}

Correspondence should be addressed to P O McGowan: patrick.mcgowan@utoronto.ca

This paper is part of a thematic section on 30 Years of the Developmental Endocrinology of Health and Disease. The guest editors for this section were Sean Limesand, Kent Thornburg and Jane Harding

\begin{abstract}
It has been approximately 30 years since the seminal discoveries of David Barker and his colleagues, and research is beginning to unravel the mechanisms that underlie developmental programming. The early environment of the embryo, foetus and newborn have been clearly linked to altered hypothalamic-pituitary-adrenal (HPA) function and related behaviours through the juvenile period and into adulthood. A number of recent studies have shown that these effects can pass across multiple generations. The HPA axis is highly responsive to the environment, impacts both central and peripheral systems and is critical to health in a wide variety of contexts. Mechanistic studies in animals are linking early exposures to adversity with changes in gene regulatory mechanisms, including modifications of DNA methylation and altered levels of miRNA. Similar associations are emerging from recent human studies. These findings suggest that epigenetic mechanisms represent a fundamental link between adverse early environments and developmental programming of later disease. The underlying biological mechanisms that connect the perinatal environment with modified long-term health outcomes represent an intensive area of research. Indeed, opportunities for early interventions must identify the relevant environmental factors and their molecular targets. This new knowledge will likely assist in the identification of individuals who are at risk of developing poor outcomes and for whom early intervention is most effective.
\end{abstract}

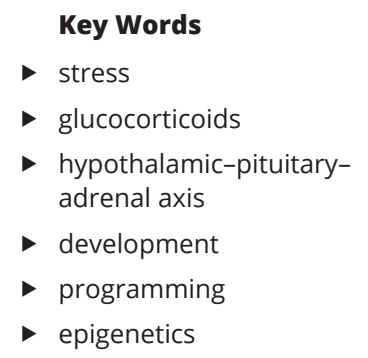

Journal of Endocrinology (2019) 242, T69-T79

\section{Introduction}

The early environment of the embryo, foetus and newborn have been clearly linked to altered hypothalamicpituitary-adrenal (HPA) function and related behaviours through the juvenile period and into adulthood (for reviews see Moisiadis \& Matthews 2014, Chan et al. 2018, McGowan \& Matthews 2018, Hamada \& Matthews 2019).
A number of recent studies have shown that these effects can pass across multiple generations. The environmental exposures can take many forms and include maternal stress/anxiety/depression, maternal obesity, maternal glucocorticoid exposure and altered level of maternal care. While early studies in the field were confined to 
animal models, more recently, they have been extended to include humans. The discoveries of David Barker, linking low birthweight to altered risk of poor cardiometabolic and mental health outcomes, were fundamental in driving the field forward (Barker \& Osmond 1986, Barker 1995). Indeed, David Phillips led studies that showed clear linkage between low birthweight, altered HPA function and associated risk for poor cardiometabolic and mental health outcomes (Phillips et al. 2000, Reynolds et al. 2001). It was these discoveries that re-ignited research (and the funding of research) in the field of developmental origins of health and disease.

Responses to environmental cues that lead to stable alterations in HPA function may initially be adaptive but in the long term, and if not appropriate for the ongoing environment, may pose a threat to health in later life. The HPA axis is highly responsive to the environment, impacts both central and peripheral systems and is critical to health in a wide variety of contexts (Reynolds 2013). Mechanistic studies in animals are linking early exposures to adversity with changes in gene regulatory mechanisms, including modifications of DNA methylation and altered levels of miRNA (Chan et al. 2018, McGowan \& Matthews 2018). Similar associations are emerging from recent human studies (Sasaki et al. 2013, Hamada \& Matthews 2019). Several genes associated with the regulation of HPA function and related behaviours are susceptible to altered epigenetic modulation. These findings suggest that epigenetic mechanisms represent a fundamental link between adverse early environments and developmental programming of later disease. The underlying biological mechanisms that connect the perinatal environment with modified long-term health outcomes and represent an intensive area of research. Indeed, opportunities for early interventions must identify the relevant environmental factors and their molecular targets. This review will focus on epigenetic mechanisms of programming of the HPA in development that impact brain function and behaviour.

\section{Developmental programming of the HPA axis and behaviour}

The HPA axis directs neuroendocrine homeostasis and the response to stress through a series of direct influences and feedback responses in the brain and periphery. Both psychological (e.g. anxiety and abuse) and physiological (e.g. hypoxia) stress result in the activation of corticotrophin-releasing hormone (CRH) neurons in the paraventricular nucleus (PVN) of the hypothalamus.
Secretion of CRH and other factors into the hypophyseal portal circulation results in increased synthesis and release of adrenocroticotrophin (ACTH) from anterior pituitary corticotrophs. ACTH in the peripheral circulation binds to melanocortin (MC) 2 receptors in the adrenal zona glomerulosa and promotes the synthesis and release of glucocorticoids (cortisol in humans, guinea pigs and sheep; corticosterone in rats and mice). Glucocorticoids produce a myriad of effects in the brain and periphery to coordinate the stress response and ultimately restore homeostasis. This response is subject to negative feedback inhibition at multiple levels of the brain (including the hippocampus, PVN) and pituitary, where glucocorticoids bind to glucocorticoid receptors (GRs) and mineralocorticoid receptors (MRs). In the hippocampus and other brain regions, MR and GR levels define the threshold of negative feedback inhibition of HPA activity (Ulrich-Lai \& Herman 2009).

Experiences during development have the potential to canalize health trajectories with long-term consequences for mental health as a result of alterations in the response to stress. For example, exposures to severe stressors early in life increase the vulnerability to multiple forms of psychopathology (De Bellis et al. 1994, Heim \& Nemeroff 2001). A primary example of these effects is the role of psychosocial stress in early life in modifying the risk for affective disorders (Heim et al. 2008). Physical and sexual abuse or severe neglect in childhood increase the risk for major depressive disorder, and this increased vulnerability is conferred, at least in part, by individual differences in endocrine and behavioural responses to stress (De Bellis et al. 1994, Heim \& Nemeroff 2001). Major depressive disorder is associated with higher levels of cortisol in response to stressors. The results of a number of studies indicate that this effect is mediated by impaired negative feedback inhibition of the HPA axis by glucocorticoids (Pariante \& Lightman 2008). In addition, depressive symptoms are sensitive to exposure to environmental stressors early in life, where adversity confers greater vulnerability to dysfunctional stress responses and major depression (Heim et al. 2008). In contrast to major depression, posttraumatic stress disorder, which also may have origins in early life is associated with reduced HPA responsiveness to stress (Morris et al. 2012, McGowan 2013). In other studies, long-term alterations in HPA function have been associated with compromised cardiometabolic outcomes (Reynolds 2013). Genotype and gender also moderate the relationship between HPA function and mental and cardiometabolic health (Carpenter et al. 2017). These factors affect the activity of 
the HPA axis and coordinate endocrine and behavioural responses in a long-term 'programmed' manner. The mechanisms that produce these effects have been the subject of intense investigation in translational medicine.

\section{Developmental plasticity and adaptation}

Developmental plasticity, defined as changes in development resulting from environmental exposures that lead to persistent modifications of phenotype, can be adaptive within a physiological range, whereas exposures outside of this range can produce non-adaptive (pathological) outcomes. Considerable evidence from animal studies indicates that the range of responses to environmental factors that modify HPA activity in early life is defined by an organism's life history. This is apparent from studies of health trajectories linked to birthweight, as well as studies of early life psychosocial stress.

Low birthweight appears to irreversibly alter developmental trajectories. Later in life, individuals born small for gestational age are at increased risk for the metabolic syndrome, showing increased risk of cardiovascular disease (hypertension), diabetes (insulin resistance) and a dysregulated HPA axis (Hales \& Barker 1992, Phillips et al. 2000, Reynolds et al. 2001). The effects of a dysregulated HPA axis in low birthweight individuals manifest in increased circulating levels of glucocorticoids and ACTH (Phillips et al. 2000, Reynolds et al. 2001). As such, fetal growth is prioritized in the context of poor energy availability in order to maximize survival at birth, but can pose a threat to health later in life (Hanson \& Gluckman 2008). However, these health effects are highly context specific. For example, energy conservation and a reduction in somatic growth may be an advantage in poor nutritional environments (Youngson \& Whitelaw 2008), potentially increasing longevity in these environments (Ozanne \& Hales 2004). In this context, maternal cues that reliably predict the later life environment are critical to the programming of appropriate responses in offspring (Bateson et al. 2014).

Early adversity profoundly impacts both HPA function and behaviours; however, the effects are highly species specific and this likely results from both differences in neurodevelopmental trajectories and glucocorticoid sensitivity. Outcomes are also very much dependent on the nature of the stressor, the timing and duration of exposure and the sex of the offspring. In addition, effects are dynamic such that phenotypes can differ depending on the age of the offspring at the time of assessment, and in females, the stage of the reproductive cycle
(Hamada \& Matthews 2019). In humans, maternal psychosocial stress and increased maternal cortisol through the first and second trimester were linked to elevated adrenocortical responses to stress in newborns and at 5 years of age (Davis et al. 2011). In contrast, in another study, where mothers experienced high levels of anxiety late in pregnancy, infants showed increased cortisol responsiveness at 5 weeks, but decreased responses at 8 weeks and 2 years (Tollenaar et al. 2011). A reduced HPA responsiveness to stress has also been reported in adolescent children of mothers who had experienced high levels of anxiety and depression in pregnancy (Vedhara et al. 2012, O'Donnell et al. 2013). A number of human studies have shown links between increased maternal stress and cortisol levels and neurodevelopmental outcomes in children, including increased ADHD-, ASD- and anxiety symptomology, as well as altered learning and memory, many of which were sex dependent (LeWinn et al. 2009, Ronald et al. 2010, Davis \& Sandman 2012, Walder et al. 2014). Interestingly, a recent study has shown increased maternal salivary cortisol in the third trimester to associate with increased negative emotionality in female infants but reduced negative emotionality in male infants (Braithwaite et al. 2017).

Maternal and fetal stress results in increased glucocorticoid levels in the foetus; indeed, it is likely that early exposure to excess glucocorticoid represents one of the drivers for long-term programming of HPA function and stress-related behaviours. Fetal glucocorticoid exposure is also highly clinically relevant as pregnant women at risk of delivering preterm are treated with synthetic glucocorticoids (sGC) to mature the fetal lungs and decrease the incidence of respiratory distress in newborns (National Institutes of Health Consensus Development Panel 2001). Preterm birth occurs in approximately 10\% of all pregnancies. As a result, a large number of infants are exposed to sGC in the second half of gestation. Further, given the difficulty of accurately predicting preterm birth, many infants from mothers treated with sGC are actually born at term ( $30 \%)$ (Murphy et al. 2008). Previous studies in humans have demonstrated that prenatal exposure to a single course of sGC can result in 6- to 10-year old children who exhibit reduced thickness of the cingulate cortex (an area associated with affective disorders) and increased HPA responsiveness to psychosocial stress (Trier Social Stress Test; TSST) (Alexander et al. 2012). Interestingly, the latter affect was more prevalent in girls than in boys (Alexander et al. 2012, Davis et al. 2013). Importantly, all the children investigated were born at normal term. Very recently, the group has gone on to show in the same children in adolescence (14-18 years) that prenatal sGC exposure resulted in significant changes in 
fronto-parietal brain function, affecting multiple aspects of adaptive cognitive and behavioural control (Ilg et al. 2018). Further, HPA responsiveness to the TSST remained elevated in adolescents whose mothers were treated with sGC (Ilg et al. 2019). Another very recent study has linked prenatal sGC exposure to increased incidence of child mental health and behavioural disorders in a large Finnish cohort; interestingly, the associations held in both preterm and termborn children (Wolford et al. 2019). These human studies indicate that maternal stress/anxiety in pregnancy together with exposure to sGC can lead to long-term effects on HPA function, neurodevelopmental function and emotionality. However, it should be noted that the majority of studies that have undertaken detailed phenotyping in children have been retrospective in nature, and some confounding factors may be present. Notwithstanding, an enormous number of animal studies, including those in primates, sheep, guinea pigs, rats, mice and other species, have reported similar longterm effects on HPA function and behaviours.

\section{Epigenetic mechanisms of developmental programming}

Epigenetic mechanisms include modifications of chromatin structure, non-coding RNA and modifications of the DNA itself through the addition of methylation. Epigenetic modifications were once thought to program cell fate during development and remain immutable thereafter. However, evidence of their contributions to human disease and findings that epigenetic modifications are responsive to therapeutic interventions have attracted considerable interest (Egger et al. 2004). In addition, a substantial body of research over the past 15 years indicates that epigenetic modifications at some genetic loci are sensitive to environmental factors. It is clear that a portion of variation in epigenetic modifications is derived from genotype and stochastic effects (Bjornsson et al. 2004, Petronis 2010); however, the degree to which genetic and stochastic factors influence neurological phenotypes remains poorly understood (van Dongen et al. 2016, Feinberg 2018). The role of epigenetic modifications as potential causal mechanisms in disease is often not assessed due to the retrospective nature of many investigations. Nonetheless, as epigenetic modifications integrate environmental and genetic factors, they constitute potential biomarkers of individual differences relevant to developmental health trajectories.

A number of studies have identified epigenetic modifications in candidate genes associated with the developmental programming of the HPA and related behaviours. Programming involving epigenetic modifications of DNA methylation and histone acetylation that affect GR expression in brain regions that regulate HPA-negative feedback in the hippocampus (Weaver et al. 2004, Mueller \& Bale 2008, McGowan et al. 2009) have been complemented by studies showing DNA methylation modifications in other candidate genes, including arginine vasopressin ( $A v p)$ and $\mathrm{Crh}$ (Murgatroyd et al. 2009, Korosi et al. 2010, Wu et al. 2014). These studies have also demonstrated that epigenetic modifications in multiple brain regions are associated with basal and stressinduced HPA regulation (Murgatroyd et al. 2009, Korosi et al. 2010, Wu et al. 2014).

\section{Environmental factors that drive HPA programming}

The studies of candidate genes described earlier have provided important 'proof of principle' that epigenetic modifications are associated with early life environmental programming of genes central to HPA axis function. However, the degree to which exposures in early life that modify HPA activity occur across other genomic loci is an active question. For example, we found hundreds of DNA methylation differences associated with early life experience distributed across a 6.5 million base pair region containing the GR gene in both rats and humans (McGowan et al. 2011, Suderman et al. 2012). These differences occurred in nonrandom patterns that were associated with regulatory regions such as promoters, forming clusters covering as many as 1 million base pairs of both coding and non-coding sequence in both species. Research in this area is rapidly evolving and continues to provide new insight into stress regulation; therefore, our review of this research must be selective. Below, we describe examples from our group and others aimed at examining epigenetic modifications associated with developmental programming of HPA function and related behaviours.

\section{Predator stress exposures during pregnancy}

In a series of studies, we examined the ability of predator cues to elicit epigenetic modifications of stress-sensitive genes in the brain. The strong evolutionary pressures exerted by predators on prey species are such that even nonlethal exposure to predator cues shape behavioural, physiological and endocrine phenotypes in prey species 
(St-Cyr \& McGowan 2018). Rodents exposed to predator odours (urine, gland secretions), show increased antipredator behaviours, including refuging and vigilance, and, in cases of chronic exposure, weight loss and decreased body condition. Interestingly, many of these impacts are also observed in non-mammalian species (see Lima 1998), indicating that they represent evolutionarily conserved adaptations to stressors.

We exposed pregnant female mice to randomized presentations of predator odours during the last half of pregnancy and examined the phenotype of adult offspring. Offspring born to mothers exposed in pregnancy showed increased stress-related behaviours, including defensive and risk assessment behaviours. The response was sex specific. Male offspring from predator odour-exposed dams visited the area proximal to a source of predator odour less frequently than unexposed control offspring (St-Cyr \& McGowan 2015). Female offspring showing enhanced HPA activation to a first presentation of predator odour in adulthood, while baseline levels of glucocorticoids remained unaltered by the prenatal exposure. Predator odour exposure in pregnancy also affected food foraging and exploratory behaviour in offspring in standard laboratory tasks examining anxietylike behaviour and also under conditions of simulated predator threat (St-Cyr et al. 2018a). Similar results were obtained in rats (St-Cyr et al. 2017).

In adulthood, female offspring born to predatorexposed dams showed an increase in stress-related gene transcription in the hippocampus and amygdala. For example, brain-derived neurotrophic factor (Bdnf) transcript was reduced in the hippocampus, whereas corticotrophin-releasing factor receptor 1 (Crfr 1 ) transcript was increased in the amygdala. Rats showed increased transcription of fk506-binding protein 5 ( Fkbp5) and $G r$ in the amygdala. These alterations in transcript abundance were correlated with DNA methylation modifications of specific CpG sites in intron $\mathrm{V}$ of the Fkbp5 gene and exon IV of the $B d n f$ gene. Programming of epigenetic modifications in gene networks regulating other aspects of neuroendocrine function have not been explored, but are likely. We found that mice offspring prenatally exposed to predator odour displayed modifications of hypothalamic-pituitary-thyroid function through increased circulating thyroxine and thyroid hormone receptor $\alpha$ within the PVN and decreased transthyretin in the liver in association with increased energy mobilization in mice (St-Cyr et al. 2018b). Whether these alterations confer differences in fitness is unknown. However, similar phenotypes have been observed in wild animals
(Clinchy et al. 2010). For example, snowshoe hares are subject to cycles of predation risk associated with alterations in HPA responsiveness and reproductive senescence (Love et al. 2013, Lavergne et al. 2014).

\section{Synthetic glucocorticoid exposures during pregnancy}

Prenatal exposure to sGC has been shown to influence HPA and stress-related behaviours in offspring in a number of animal models, including primates, sheep, guinea pigs, rats and mice (Moisiadis \& Matthews 2014, McGowan \& Matthews 2018, Hamada \& Matthews 2019). Studies from our group in the guinea pig have shown that single and repeated in utero exposure to sGC results in increased HPA responsiveness to a novel environment in juvenile offspring, with no effect on basal cortisol levels (Moisiadis et al. 2017, 2018). Interestingly, these effects were confined to females with no effect in juvenile males. In an earlier study, we had shown that repeated maternal treatment with sGC resulted in a decrease in basal and activated adrenocortical function in young adult male offspring at 70 days of age (Liu et al. 2001). Interestingly, young adult female offspring exhibited increased basal and activated HPA function in the follicular and oestrous phase of the cycle, but reduced function (like the males) in the luteal phase of the cycle (Liu et al. 2001). Subsequent studies, undertaken in older adult offspring indicated that the effects of prenatal exposure to sGC on HPA function are less evident as animals age, though long-term effects on cardiometabolic function remained (Banjanin et al. 2004, Dunn et al. 2010, Moisiadis et al. 2018). At the level of behaviours, prenatal exposure to sGC resulted in increased ambulatory activity in the open field, and modified sensory motor gating (attention) in juvenile and adult offspring, though these effects were dependant on sex, age and the dose of in utero exposure to sGC (single vs multiple treatments). A number of our studies have linked changes in HPA function and behaviours to modified gene expression in the pituitary, hypothalamus, hippocampus and prefrontal cortex (Liu et al. 2001, Banjanin et al. 2004, Dunn et al. 2010, Moisiadis et al. 2017, Constantinof et al. 2019). Together, these studies indicate that there are profound effects of prenatal exposure to sGC on HPA function and behaviours, but that these effects are sex specific and depend on the age at which a particular outcome is measured. In females, there is clearly interaction between the programming effects of GCs and the stage of the reproductive cycle.

A series of studies have been undertaken to determine the potential mechanisms by which fetal exposure to sGC 
leads to long-term changes in endocrine function and behaviours. In late gestation, there is a natural increase in endogenous glucocorticoid in the fetal circulation in most mammalian species. This surge is critical in maturing several fetal organ systems (e.g. lung, kidney and thyroid) in preparation for neonatal life. We have recently shown that the surge in endogenous glucocorticoid is associated with altered expression of over 1000 genes in the fetal guinea pig hippocampus and that there are parallel changes in histone acetylation and reductions in DNA methylation (Crudo et al. 2013a,b). Exposure of the foetus to sGC, prior to the natural glucocorticoid surge resulted in changes in hippocampal gene expression and DNA methylation; however, importantly a different gene set was affected. Also, temporal analysis following sGC exposure revealed that the effects are dynamic as the transcriptional, histone acetylation and DNA methylation landscapes were quite different after acute ( $24 \mathrm{~h}$ after sGC) and longer term (14 days after sGC) exposures (Crudo et al. 2013a,b). Together, the studies would suggest that the natural glucocorticoid surge is important in maturing the fetal hippocampus and that this is mediated through epigenetic mechanisms. Further, this process may be perturbed by early exposure to sGC.

\section{Transgenerational programming}

There is great interest in whether exposures of the parental generation can affect offspring across multiple generations as a result of epigenetic modifications, though research in this area has attracted controversy. Transgenerational effects can be distinguished from intergenerational effects limited to exposures of the offspring (F1) generation as a direct consequence of exposure effects on physiology or behaviour of the parental (F0) generation. It should be noted that exposure of the F2 generation can also be direct, since primordial germ cells of the $\mathrm{F} 2$ generation are present in the developing F1 offspring. The erasure of DNA methylation that occurs during gonadal sex determination (i.e. with the formation of mature sperm in males and at each cycle with the formation of mature oocytes in females) and again at fertilization is nearly complete. One exception is imprinted genes which maintain patterns of DNA methylation during fertilization and are transcribed in a parent-of-origin manner. Interestingly, in contrast to other somatic cell types, a number of genes in the brain are also regulated in a parent-of-origin manner by DNA methylation (Perez et al. 2016), though their role in HPArelated phenotypes is not known. In addition, recent studies have discovered non-coding exosomal RNAs present in germ cells and have proposed mechanisms of transgenerational transmission of HPA dysfunction and stress-related phenotypes (Gapp et al. 2014, Rodgers et al. 2015). These studies have suggested that epigenetic modifications in germ cells are possible vectors for the transgenerational transmission of phenotypes. However, the molecular mechanisms linking altered germ cell RNA species to modified phenotype remain to be determined.

Animal studies have shown that stress or glucocorticoid exposure in the maternal or paternal generation is associated with altered HPA function in second-generation offspring. For example, adult female F2 offspring born to mothers that had been exposed to social stress during gestation exhibited increased HPA reactivity to stress. These changes in F2 females were associated with decreased hippocampal $\mathrm{Gr}$ and $\mathrm{Mr}$ expression and increased $\mathrm{Crh}$ expression in the PVN, indicative of impaired glucocorticoid negative feedback sensitivity. In contrast, male F2 offspring exhibited increased hippocampal Gr expression and attenuated HPA reactivity to acute stress (Grundwald \& Brunton 2015). In a recent series of studies, we have shown that prenatal exposure to sGC results in HPA and behavioural phenotypes that are transmitted across multiple generations through maternal and paternal routes (Iqbal et al. 2012, Moisiadis et al. 2017, 2018, Constantinof et al. 2019). Maternal treatment with sGC resulted in first-, second- and thirdgeneration juvenile offspring that exhibited altered locomotor activity in an open-field and modified HPA function. Effects were most prominent following paternal transmission in female offspring (Moisiadis et al. 2017). Subsequent studies, using RNA-seq showed altered gene expression in the hypothalamic PVN and the prefrontal cortex across three generations (Moisiadis et al. 2017, Constantinof et al. 2019). Together, the studies indicate that maternal stress and sGC exposure can lead to changes in HPA function and behaviours that are evident across multiple generations. The mechanisms that underlie this transmission require further elucidation.

Recent studies have shown that paternal exposure, prior to conception, can also have effects on HPA function and behaviours in offspring. Adult male mice exposed to glucocorticoids for 4 weeks prior to mating sired male offspring that showed increased locomotor activity and anxiety and female offspring that exhibited impaired fear extinction and memory (Short et al. 2016, Yeshurun et al. 2017). Male and female F2 offspring displayed lower levels of anxiety behaviour and, in males, increased depression-like behaviour (Short et al. 2016). At the level of paternal transmission, glucocorticoid exposure in the 
F0 males was associated with alterations in levels of a number of miRNAs in sperm, including several predicted to interact with growth factor-related genes such as $B d n f$ and insulin-like growth factor 2 (Igf2) (Short et al. 2016). Other studies have shown that paternal stress is associated with reduced HPA reactivity and increased expression of nine miRNAs in the sperm of F1 offspring (Rodgers et al. 2013). Remarkably, zygote microinjection of these nine sperm miRNAs recapitulated the effects of paternal stress (Rodgers et al. 2015). Despite these intriguing findings, the role of specific miRNAs in sperm in relation to stressrelated brain function remains uncertain; an area that requires further investigation.

Human studies of intergenerational transmission of severe maternal stress/trauma (war, natural disasters, domestic violence, terrorist attacks) indicate that maternal (and possibly paternal) stress is associated with altered cortisol responses in children and differential methylation of the GR promoter in peripheral blood (Radtke et al. 2011, McGowan 2013, Yehuda et al. 2014, Kertes et al. 2016). A few genome-wide discovery studies have implicated other genes (particularly genes involved in immune function) (Cao-Lei et al. 2014, 2015). In contrast, non-traumatic stress does not appear as strongly associated with the same DNA methylation modifications in peripheral blood (Tyrka et al. 2012). It appears that the type or severity of stressor exposure is critical. To date, a few epidemiological studies examining metabolic/growth-related outcomes (e.g. Heijmans et al. 2008, Veenendaal et al. 2013) in relation to epigenetic modifications are strongly suggestive of the programming of transgenerational effects in humans. However, evidence of transgenerational programming of HPA is lacking in humans. Studies of well-characterized cohorts are needed, as is consideration of alternative explanations for the transmission of epigenetic effects that do not involve cellular reprogramming.

\section{Challenges of epigenetic and omic approaches}

Translational studies of epigenetic modifications associated with HPA and related behaviours have focused largely on DNA methylation. This focus is primarily due to the fact that relative to other epigenetic modifications of histones or non-coding RNA, DNA methylation is considered a relatively stable epigenetic modification. However, it is important to note that transcription factors, not DNA methylation modifications themselves, are the drivers of gene regulation. This means that a true mechanistic understanding of how epigenetic modifications are involved in transcriptional changes requires the identification of mechanisms and contexts that promote the differential binding of transcription factors to relevant regions of DNA such as gene regulatory elements. Evidence for how specific transcription factors target these regions is also needed. One example of such an approach is studies of GR binding to glucocorticoid response elements in the fetal hippocampus in relation to sGC exposure, in utero (Crudo et al. 2013a). Such mechanistic studies are challenging, particularly in humans.

As mentioned earlier in this review, the majority of studies examining the developmental programming of epigenetic modifications in relation to phenotypes are retrospective. In human studies, subjects are sometimes examined years after the putative exposure. Developmental studies that examine epigenetic modifications before, during and after developmental exposures can be used to establish causal relationships between epigenetic modifications and exposures. They are also important in establishing phenotypes sensitive to differences in cell proportions, hormone exposures or post-translational modifications to non-histone proteins that may influence trajectories of health and disease at the time of exposure. The goal would be to distinguish these effects on phenotypes arising from true cellular reprogramming events that require epigenetic modifications that must be maintained within a given cell type (Lappalainen \& Greally 2017). Longitudinal designs can also be important in determining the extent to which epigenetic modifications prime future responses to stressors that then lead to pathological outcomes (Ashbrook et al. 2018), as well as interventions that help to buffer stress (Gapp et al. 2016). In contexts that purport to investigate transgenerational epigenetic effects/inheritance, the role of genetic selection should also be considered, though in practice, this may be difficult to rule out.

In studies that integrate genome-wide approaches, using multiple levels of analysis (transcriptomic, epigenomic, proteomic), data analysis is complex. Currently, there are many competing methods for the analysis of information obtained from high-throughput sequencing, as well as for the integration of different data types. There is a need for standardization of tools and pipelines that are also accessible to researchers outside the immediate bioinformatics community (Gruning et al. 2017). In addition, standard methods to examine the degree of DNA methylation attributable to cell heterogeneity are based on a subset of clearly defined cell types from healthy donors (Cardenas et al. 2016). Even reference-free methods (e.g. Rahmani et al. 2017) assume that phenotype-related changes exceed cell-type-specific 
changes, which may not be accurate (Breton et al. 2017). An additional challenge is that these techniques are based on microarray technologies, such that the number of sites amenable to distinguish cell types is limited to a fraction of CpG sites that can be potentially methylated (e.g. $<2 \%$ in the case of Infinium microarrays). Even where technically feasible, some issues remain regarding the use of cell separation techniques such as Fluorescence-Assisted Cell Sorting, where significant cross-contamination has been noted among cell types. For example, hypomethylated nucleated red blood cells in human cord blood show heterotopic interactions with T-cells, monocytes and B-cells that significantly affect the methylation profiles (de Goede et al. 2015). Novel techniques such as the Assay for Transposase-Accessible Chomatin using sequencing (ATAC-seq) also offer the potential to integrate studies of chromatin remodelling with other functional genomic and epigenetic data in an efficient and cost-effective manner (Buenrostro et al. 2015).

\section{Conclusions}

It is clear that maternal stress/anxiety and glucocorticoid exposure during pregnancy can lead to long-term effects on HPA function and stress-related behaviours in offspring. More recent evidence indicates that paternal stress and glucocorticoid exposure prior to conception can also have profound influences on subsequent offspring phenotype. Importantly, it appears that these phenotypes can be maintained across multiple generations. There is considerable heterogeneity in the literature regarding the nature of the programmed phenotype in offspring. There are very significant species differences and the timing and dose of exposure are critical. It is also evident that sex of the offspring and the age at which assessment of phenotypic outcome is undertaken are important. Indeed, to understand the programming effects of an early environment assessment must be undertaken at multiple stages of the life course, and in females, at different stages of the reproductive cycle.

It is important to consider the potential population advantage of programming (from Drosophila to human), why some individuals are more resilient than others, as well as the mechanistic roots. While the latter has become a focus of many labs, it is important to emphasize very high-quality and detailed phenotyping, otherwise important elements that are relevant to humans will be missed. For example, it is not sufficient to test how an early exposure modifies the time to learn, but also to determine how strategies of learning might be affected. The latter is of critical relevance for educational programmes.

There have been very rapid advances in our understanding of the mechanisms that underlie developmental programming, but this has raised new and important questions and challenges. There has been much focus on the potential of epigenetic mechanisms to link early experience/exposures to long-term phenotypic outcomes. Many of the molecular tools are becoming more available and 'main stream'; however, these are complex molecular processes that need to be carefully investigated. For example, DNA methylation is highly dependent on cell type, and early exposures may impact cell populations that will create challenges in interpretation if mixed cell populations are tested. Bioinformatic tools to assist in overcoming this challenge and others require further development. It is also important to make such tools accessible for the non-bioinformatician.

It has been known for some time that the effects of maternal and paternal stress/anxiety and glucocorticoid exposure can manifest across multiple generations via both maternal and paternal transmission. Recent elegant studies have begun to identify potential mechanisms (e.g. miRNA and tRNA) by which such transmission may occur, but many important questions remain. For example, how does altered sperm miRNA alter embryo, fetal and offspring development leading to altered neuroendocrine and behavioural phenotypes. This is indeed an exciting area of research.

It has been approximately 30 years since the seminal discoveries of David Barker and his colleagues, and research is beginning to unravel the mechanisms that underlie developmental programming. This new knowledge will likely help us to identify individuals who are at risk of developing poor outcomes and for whom early intervention is most efficacious. These interventions will be refined further by advancing our understanding of the drivers and targets. Ultimately, we may be able to prevent, ameliorate or reverse the poor health outcomes associated with early adversity.

\section{Declaration of interest}

The authors declare that there is no conflict of interest that could be perceived as prejudicing the impartiality of this review.

\section{Funding}

The authors work cited herein was supported by the Canadian Institutes for Health Research (S G M, P O M), the Natural Sciences and Engineering Research Council of Canada (S G M, P O M) and the US Department of Defense (P O M). 


\section{References}

Alexander N, Rosenlocher F, Stalder T, Linke J, Distler W, Morgner J \& Kirschbaum C 2012 Impact of antenatal synthetic glucocorticoid exposure on endocrine stress reactivity in term-born children. Journal of Clinical Endocrinology and Metabolism 97 3538-3544. (https://doi. org/10.1210/jc.2012-1970)

Ashbrook DG, Hing B, Michalovicz LT, Kelly KA, Miller JV, de Vega WC, Miller DB, Broderick G, O'Callaghan JP \& McGowan PO 2018 Epigenetic impacts of stress priming of the neuroinflammatory response to sarin surrogate in mice: a model of Gulf War illness. Journal of Neuroinflammation 15 86. (https://doi.org/10.1186/s12974-018-1113-9)

Banjanin S, Kapoor A \& Matthews SG 2004 Prenatal glucocorticoid exposure alters hypothalamic-pituitary-adrenal function and blood pressure in mature male guinea pigs. Journal of Physiology $\mathbf{5 5 8}$ 305-318. (https://doi.org/10.1113/jphysiol.2004.063669)

Barker DJ 1995 Fetal origins of coronary heart disease. BMJ 311 171-174 (https://doi.org/10.1136/bmj.311.6998.171)

Barker DJ \& Osmond C 1986 Infant mortality, childhood nutrition, and ischaemic heart disease in England and Wales. Lancet 1 1077-1081. (https://doi.org/10.1016/S0140-6736(86)91340-1)

Bateson P, Gluckman P \& Hanson M 2014 The biology of developmental plasticity and the predictive adaptive response hypothesis. Journal of Physiology 592 2357-2368. (https://doi.org/10.1113/ jphysiol.2014.271460)

Bjornsson HT, Fallin MD \& Feinberg AP 2004 An integrated epigenetic and genetic approach to common human disease. Trends in Genetics 20 350-358. (https://doi.org/10.1016/j.tig.2004.06.009)

Braithwaite EC, Pickles A, Sharp H, Glover V, O'Donnell KJ, Tibu F \& Hill J 2017 Maternal prenatal cortisol predicts infant negative emotionality in a sex-dependent manner. Physiology and Behavior 175 31-36. (https://doi.org/10.1016/j.physbeh.2017.03.017)

Breton CV, Marsit CJ, Faustman E, Nadeau K, Goodrich JM, Dolinoy DC, Herbstman J, Holland N, LaSalle JM, Schmidt R, et al. 2017 Smallmagnitude effect sizes in epigenetic end points are important in children's environmental health studies: the children's Environmental Health and Disease Prevention Research Center's Epigenetics Working Group. Environmental Health Perspectives 125 511-526. (https://doi.org/10.1289/EHP595)

Buenrostro JD, Wu B, Chang HY \& Greenleaf WJ 2015 ATAC-seq: a method for assaying chromatin accessibility genome-wide. Current Protocols in Molecular Biology 109 21.29.1-21.29.9. (https://doi. org/10.1002/0471142727.mb2129s109)

Cao-Lei L, Massart R, Suderman MJ, Machnes Z, Elgbeili G, Laplante DP, Szyf M \& King S 2014 DNA methylation signatures triggered by prenatal maternal stress exposure to a natural disaster: project ice storm. PLoS One 9 e107653. (https://doi.org/10.1371/journal. pone.0107653)

Cao-Lei L, Dancause KN, Elgbeili G, Massart R, Szyf M, Liu A, Laplante DP \& King S 2015 DNA methylation mediates the impact of exposure to prenatal maternal stress on BMI and central adiposity in children at age 131/2 years: project ice storm. Epigenetics 10 749-761. (https://doi. org/10.1080/15592294.2015.1063771)

Cardenas A, Allard C, Doyon M, Houseman EA, Bakulski KM, Perron P, Bouchard L \& Hivert MF 2016 Validation of a DNA methylation reference panel for the estimation of nucleated cells types in cord blood. Epigenetics 11 773-779. (https://doi.org/10.1080/15592294.20 16.1233091)

Carpenter T, Grecian SM \& Reynolds RM 2017 Sex differences in early-life programming of the hypothalamic-pituitary-adrenal axis in humans suggest increased vulnerability in females: a systematic review. Journal of Developmental Origins of Health and Disease 8 244-255. (https://doi. org/10.1017/S204017441600074X)

Chan JC, Nugent BM \& Bale TL 2018 Parental advisory: maternal and paternal stress can impact offspring neurodevelopment.
Biological Psychiatry 83 886-894. (https://doi.org/10.1016/j. biopsych.2017.10.005)

Clinchy M, Schulkin J, Zanette LY, Sheriff MJ, McGowan PO \& Boonstra R 2010 The neurological ecology of fear: insights neuroscientists and ecologists have to offer one another. Frontiers in Behavioral Neuroscience 4 21. (https://doi.org/10.3389/fnbeh.2011.00021)

Constantinof A, Moisiadis VG, Kostaki A, Szyf M \& Matthews SG 2019 Antenatal glucocorticoid exposure results in sex-specific and transgenerational changes in prefrontal cortex gene transcription that relate to behavioural outcomes. Scientific Reports 9 764. (https://doi. org/10.1038/s41598-018-37088-3)

Crudo A, Petropoulos S, Suderman M, Moisiadis VG, Kostaki A, Hallett M, Szyf M \& Matthews SG 2013a Effects of antenatal synthetic glucocorticoid on glucocorticoid receptor binding, DNA methylation, and genome-wide mRNA levels in the fetal male hippocampus. Endocrinology 154 4170-4181. (https://doi.org/10.1210/en.2013-1484)

Crudo A, Suderman M, Moisiadis VG, Petropoulos S, Kostaki A, Hallett M, Szyf M \& Matthews SG 2013b Glucocorticoid programming of the fetal male hippocampal epigenome. Endocrinology 154 1168-1180. (https://doi.org/10.1210/en.2012-1980)

Davis EP \& Sandman CA 2012 Prenatal psychobiological predictors of anxiety risk in preadolescent children. Psychoneuroendocrinology $\mathbf{3 7}$ 1224-1233. (https://doi.org/10.1016/j.psyneuen.2011.12.016)

Davis EP, Glynn LM, Waffarn F \& Sandman CA 2011 Prenatal maternal stress programs infant stress regulation. Journal of Child Psychology and Psychiatry, and Allied Disciplines 52 119-129. (https://doi.org/10.1111/ j.1469-7610.2010.02314.x)

Davis EP, Sandman CA, Buss C, Wing DA \& Head K 2013 Fetal glucocorticoid exposure is associated with preadolescent brain development. Biological Psychiatry $\mathbf{7 4}$ 647-655. (https://doi. org/10.1016/j.biopsych.2013.03.009)

De Bellis MD, Chrousos GP, Dorn LD, Burke L, Helmers K, Kling MA, Trickett PK \& Putnam FW 1994 Hypothalamic-pituitary-adrenal axis dysregulation in sexually abused girls. Journal of Clinical Endocrinology and Metabolism 78 249-255. (https://doi.org/10.1210/ jcem.78.2.8106608)

de Goede OM, Razzaghian HR, Price EM, Jones MJ, Kobor MS, Robinson WP \& Lavoie PM 2015 Nucleated red blood cells impact DNA methylation and expression analyses of cord blood hematopoietic cells. Clinical Epigenetics 7 95. (https://doi.org/10.1186/s13148-015-0129-6)

Dunn E, Kapoor A, Leen J \& Matthews SG 2010 Prenatal synthetic glucocorticoid exposure alters hypothalamic-pituitary-adrenal regulation and pregnancy outcomes in mature female guinea pigs. Journal of Physiology 588 887-899. (https://doi.org/10.1113/ jphysiol.2009.182139)

Egger G, Liang G, Aparicio A \& Jones PA 2004 Epigenetics in human disease and prospects for epigenetic therapy. Nature $\mathbf{4 2 9} 457-463$. (https://doi.org/10.1038/nature02625)

Feinberg AP 2018 The key role of epigenetics in human disease prevention and mitigation. New England Journal of Medicine $\mathbf{3 7 8}$ 1323-1334. (https://doi.org/10.1056/NEJMra1402513)

Gapp K, Jawaid A, Sarkies P, Bohacek J, Pelczar P, Prados J, Farinelli L, Miska E \& Mansuy IM 2014 Implication of sperm RNAs in transgenerational inheritance of the effects of early trauma in mice. Nature Neuroscience 17 667-669. (https://doi.org/10.1038/nn.3695)

Gapp K, Bohacek J, Grossmann J, Brunner AM, Manuella F, Nanni P \& Mansuy IM 2016 Potential of environmental enrichment to prevent transgenerational effects of paternal trauma. Neuropsychopharmacology 41 2749-2758. (https://doi.org/10.1038/npp.2016.87)

Grundwald NJ \& Brunton PJ 2015 Prenatal stress programs neuroendocrine stress responses and affective behaviors in second generation rats in a sex-dependent manner. Psychoneuroendocrinology 62 204-216. (https://doi.org/10.1016/j.psyneuen.2015.08.010)

Gruning BA, Fallmann J, Yusuf D, Will S, Erxleben A, Eggenhofer F, Houwaart T, Batut B, Videm P, Bagnacani A, et al. 2017 The RNA workbench: best practices for RNA and high-throughput sequencing https://joe.bioscientifica.com

https://doi.org/10.1530/JOE-19-0057 (c) 2019 Society for Endocrinology Published by Bioscientifica Ltd.
Printed in Great Britain 
bioinformatics in Galaxy. Nucleic Acids Research 45 W560-W566. (https://doi.org/10.1093/nar/gkx409)

Hales CN \& Barker DJ 1992 Type 2 (non-insulin-dependent) diabetes mellitus: the thrifty phenotype hypothesis. Diabetologia 35 595-601. (https://doi.org/10.1007/BF00400248)

Hamada H \& Matthews SG 2019 Prenatal programming of stress responsiveness and behaviours: progress and perspectives. Journal of Neuroendocrinology 31 e12674. (https://doi.org/10.1111/jne.12674)

Hanson MA \& Gluckman PD 2008 Developmental origins of health and disease: new insights. Basic \& Clinical Pharmacology \& Toxicology 102 90-93. (https://doi.org/10.1111/j.1742-7843.2007.00186.x)

Heijmans BT, Tobi EW, Stein AD, Putter H, Blauw GJ, Susser ES, Slagboom PE \& Lumey LH 2008 Persistent epigenetic differences associated with prenatal exposure to famine in humans. PNAS $\mathbf{1 0 5}$ 17046-17049. (https://doi.org/10.1073/pnas.0806560105)

Heim C \& Nemeroff CB 2001 The role of childhood trauma in the neurobiology of mood and anxiety disorders: preclinical and clinical studies. Biological Psychiatry 49 1023-1039. (https://doi.org/10.1016/ S0006-3223(01)01157-X)

Heim C, Newport DJ, Mletzko T, Miller AH \& Nemeroff CB 2008 The link between childhood trauma and depression: insights from HPA axis studies in humans. Psychoneuroendocrinology 33 693-710. (https://doi. org/10.1016/j.psyneuen.2008.03.008)

Ilg L, Klados M, Alexander N, Kirschbaum C \& Li SC 2018 Long-term impacts of prenatal synthetic glucocorticoids exposure on functional brain correlates of cognitive monitoring in adolescence. Scientific Reports 8 7715. (https://doi.org/10.1038/s41598-018-26067-3)

Ilg L, Kirschbaum C, Li SC, Rosenlocher F, Miller R \& Alexander N 2019 Persistent effects of antenatal synthetic glucocorticoids on endocrine stress reactivity from childhood to adolescence. Journal of Clinical Endocrinology and Metabolism 104 827-834. (https://doi.org/10.1210/ jc.2018-01566)

Iqbal M, Moisiadis VG, Kostaki A \& Matthews SG 2012 Transgenerational effects of prenatal synthetic glucocorticoids on hypothalamicpituitary-adrenal function. Endocrinology 153 3295-3307. (https://doi. org/10.1210/en.2012-1054)

Kertes DA, Kamin HS, Hughes DA, Rodney NC, Bhatt S \& Mulligan CJ 2016 Prenatal maternal stress predicts methylation of genes regulating the hypothalamic-pituitary-adrenocortical system in mothers and newborns in the Democratic Republic of Congo. Child Development $\mathbf{8 7}$ 61-72. (https://doi.org/10.1111/cdev.12487)

Korosi A, Shanabrough M, McClelland S, Liu ZW, Borok E, Gao XB, Horvath TL \& Baram TZ 2010 Early-life experience reduces excitation to stress-responsive hypothalamic neurons and reprograms the expression of corticotropin-releasing hormone. Journal of Neuroscience 30 703-713. (https://doi.org/10.1523/JNEUROSCI.4214-09.2010)

Lappalainen T \& Greally JM 2017 Associating cellular epigenetic models with human phenotypes. Nature Reviews: Genetics 18 441-451. (https://doi.org/10.1038/nrg.2017.32)

Lavergne SG, McGowan PO, Krebs CJ \& Boonstra R 2014 Impact of high predation risk on genome-wide hippocampal gene expression in snowshoe hares. Oecologia 176 613-624. (https://doi.org/10.1007/ s00442-014-3053-0)

LeWinn KZ, Stroud LR, Molnar BE, Ware JH, Koenen KC \& Buka SL 2009 Elevated maternal cortisol levels during pregnancy are associated with reduced childhood IQ. International Journal of Epidemiology 38 1700-1710. (https://doi.org/10.1093/ije/dyp200)

Lima SL 1998 Nonlethal effects in the ecology of predator-prey interactions. BioScience 48 25-34. (https://doi.org/10.2307/1313225)

Liu L, Li A \& Matthews SG 2001 Maternal glucocorticoid treatment programs HPA regulation in adult offspring: sex-specific effects. American Journal of Physiology: Endocrinology and Metabolism 280 E729-E739. (https://doi.org/10.1152/ajpendo.2001.280.5.E729)

Love OP, McGowan PO \& Sheriff MJ 2013 Maternal adversity and ecological stressors in natural populations: the role of stress axis programming in individuals, with implications for populations and communities. Functional Ecology 27 81-92. (https://doi.org/10.1111/ j.1365-2435.2012.02040.x)

McGowan PO 2013 Epigenomic mechanisms of early adversity and HPA dysfunction: considerations for PTSD research. Frontiers in Psychiatry 4 110. (https://doi.org/10.3389/fpsyt.2013.00110)

McGowan PO \& Matthews SG 2018 Prenatal stress, glucocorticoids, and developmental programming of the stress response. Endocrinology 159 69-82. (https://doi.org/10.1210/en.2017-00896)

McGowan PO, Sasaki A, D'Alessio AC, Dymov S, Labonte B, Szyf M, Turecki G \& Meaney MJ 2009 Epigenetic regulation of the glucocorticoid receptor in human brain associates with childhood abuse. Nature Neuroscience 12 342-348. (https://doi.org/10.1038/ nn.2270)

McGowan PO, Suderman M, Sasaki A, Huang TC, Hallett M, Meaney MJ \& Szyf M 2011 Broad epigenetic signature of maternal care in the brain of adult rats. PLoS One 6 e14739. (https://doi.org/10.1371/ journal.pone.0014739)

Moisiadis VG \& Matthews SG 2014 Glucocorticoids and fetal programming part 1: outcomes. Nature Reviews: Endocrinology 10 391-402. (https://doi.org/10.1038/nrendo.2014.73)

Moisiadis VG, Constantinof A, Kostaki A, Szyf M \& Matthews SG 2017 Prenatal glucocorticoid exposure modifies endocrine function and behaviour for 3 generations following maternal and paternal transmission. Scientific Reports 7 11814. (https://doi.org/10.1038/ s41598-017-11635-w)

Moisiadis VG, Mouratidis A, Kostaki A \& Matthews SG 2018 A single course of synthetic glucocorticoids in pregnant guinea pigs programs behavior and stress response in two generations of offspring. Endocrinology 159 4065-4076. (https://doi.org/10.1210/en.2018-00666)

Morris MC, Compas BE \& Garber J 2012 Relations among posttraumatic stress disorder, comorbid major depression, and HPA function: a systematic review and meta-analysis. Clinical Psychology Review 32 301-315. (https://doi.org/10.1016/j.cpr.2012.02.002)

Mueller BR \& Bale TL 2008 Sex-specific programming of offspring emotionality after stress early in pregnancy. Journal of Neuroscience $\mathbf{2 8}$ 9055-9065. (https://doi.org/10.1523/JNEUROSCI.1424-08.2008)

Murgatroyd C, Patchev AV, Wu Y, Micale V, Bockmuhl Y, Fischer D, Holsboer F, Wotjak CT, Almeida OF \& Spengler D 2009 Dynamic DNA methylation programs persistent adverse effects of early-life stress. Nature Neuroscience 12 1559-1566. (https://doi.org/10.1038/nn.2436)

Murphy KE, Hannah ME, Willan AR, Hewson SA, Ohlsson A, Kelly EN, Matthews SG, Saigal S, Asztalos E, Ross S, et al. 2008 Multiple courses of antenatal corticosteroids for preterm birth (MACS): a randomised controlled trial. Lancet 372 2143-2151. (https://doi.org/10.1016/ S0140-6736(08)61929-7)

National Institutes of Health Consensus Development Panel 2001 Antenatal corticosteroids revisited: repeat courses - National Institutes of Health Consensus Development Conference Statement 2000. Obstetrics and Gynecology 98 144-150. (https://doi.org/10.1016/S00297844(01)01410-7)

O'Donnell KJ, Glover V, Jenkins J, Browne D, Ben-Shlomo Y, Golding J \& O'Connor TG 2013 Prenatal maternal mood is associated with altered diurnal cortisol in adolescence. Psychoneuroendocrinology $\mathbf{3 8}$ 1630-1638. (https://doi.org/10.1016/j.psyneuen.2013.01.008)

Ozanne SE \& Hales CN 2004 Lifespan: catch-up growth and obesity in male mice. Nature 427-411. (https://doi.org/10.1038/427411b)

Pariante CM \& Lightman SL 2008 The HPA axis in major depression: classical theories and new developments. Trends in Neurosciences $\mathbf{3 1}$ 464-468. (https://doi.org/10.1016/j.tins.2008.06.006)

Perez JD, Rubinstein ND \& Dulac C 2016 New perspectives on genomic imprinting, an essential and multifaceted mode of epigenetic control in the developing and adult brain. Annual Review of Neuroscience 39 347-384. (https://doi.org/10.1146/annurev-neuro-061010-113708)

Petronis A 2010 Epigenetics as a unifying principle in the aetiology of complex traits and diseases. Nature 465 721-727. (https://doi. org/10.1038/nature09230) https://joe.bioscientifica.com https://doi.org/10.1530/JOE-19-0057
(C) 2019 Society for Endocrinology Published by Bioscientifica Ltd. Printed in Great Britain 
Phillips DI, Walker BR, Reynolds RM, Flanagan DE, Wood PJ, Osmond C, Barker DJ \& Whorwood CB 2000 Low birth weight predicts elevated plasma cortisol concentrations in adults from 3 populations. Hypertension 35 1301-1306. (https://doi.org/10.1161/01.HYP.35.6.1301)

Radtke KM, Ruf M, Gunter HM, Dohrmann K, Schauer M, Meyer A \& Elbert T 2011 Transgenerational impact of intimate partner violence on methylation in the promoter of the glucocorticoid receptor. Translational Psychiatry 1 e21. (https://doi.org/10.1038/tp.2011.21)

Rahmani E, Schweiger R, Shenhav L, Eskin E \& Halperin E 2017 A Bayesian framework for estimating cell type composition from DNA methylation without the need for methylation reference. In Research in Computational Molecular Biology. RECOMB 2017. Lecture Notes in Computer Science, pp 207-223. Cham, Switzerland: Springer. (https:// doi.org/10.1007/978-3-319-56970-3_13)

Reynolds RM 2013 Glucocorticoid excess and the developmental origins of disease: two decades of testing the hypothesis - 2012 Curt Richter Award winner. Psychoneuroendocrinology 38 1-11. (https://doi. org/10.1016/i.psyneuen.2012.08.012)

Reynolds RM, Walker BR, Syddall HE, Andrew R, Wood PJ, Whorwood CB \& Phillips DI 2001 Altered control of cortisol secretion in adult men with low birth weight and cardiovascular risk factors. Journal of Clinical Endocrinology and Metabolism 86 245-250. (https://doi. org/10.1210/jcem.86.1.7145)

Rodgers AB, Morgan CP, Bronson SL, Revello S \& Bale TL 2013 Paternal stress exposure alters sperm microRNA content and reprograms offspring HPA stress axis regulation. Journal of Neuroscience 33 9003-9012. (https://doi.org/10.1523/JNEUROSCI.0914-13.2013)

Rodgers AB, Morgan CP, Leu NA \& Bale TL 2015 Transgenerational epigenetic programming via sperm microRNA recapitulates effects of paternal stress. PNAS 112 13699-13704. (https://doi.org/10.1073/ pnas.1508347112)

Ronald A, Pennell CE \& Whitehouse AJ 2010 Prenatal maternal stress associated with ADHD and autistic traits in early childhood. Frontiers in Psychology 1 223. (https://doi.org/10.3389/fpsyg.2010.00223)

Sasaki A, de Vega WC \& McGowan PO 2013 Biological embedding in mental health: an epigenomic perspective. Biochemistry and Cell Biology 91 14-21. (https://doi.org/10.1139/bcb-2012-0070)

Short AK, Fennell KA, Perreau VM, Fox A, O’Bryan MK, Kim JH, Bredy TW, Pang TY \& Hannan AJ 2016 Elevated paternal glucocorticoid exposure alters the small noncoding RNA profile in sperm and modifies anxiety and depressive phenotypes in the offspring. Translational Psychiatry 6 e837. (https://doi.org/10.1038/ tp.2016.109)

St-Cyr S \& McGowan PO 2015 Programming of stress-related behavior and epigenetic neural gene regulation in mice offspring through maternal exposure to predator odor. Frontiers in Behavioral Neuroscience 9 145. (https://doi.org/10.3389/fnbeh.2015.00145)

St-Cyr S \& McGowan PO 2018 Adaptation or pathology? The role of prenatal stressor type and intensity in the developmental programing of adult phenotype. Neurotoxicology and Teratology 66 113-124. (https://doi.org/10.1016/j.ntt.2017.12.003)

St-Cyr S, Abuaish S, Sivanathan S \& McGowan PO 2017 Maternal programming of sex-specific responses to predator odor stress in adult rats. Hormones and Behavior 94 1-12. (https://doi.org/10.1016/j. yhbeh.2017.06.005)

St-Cyr S, Abuaish S, Spinieli RL \& McGowan PO 2018a Maternal predator odor exposure in mice programs adult offspring social behavior and increases stress-induced behaviors in semi-naturalistic and commonly-used laboratory tasks. Frontiers in Behavioral Neuroscience 12 136. (https://doi.org/10.3389/fnbeh.2018.00136)
St-Cyr S, Abuaish S, Welch KC \& McGowan PO 2018b Maternal predator odour exposure programs metabolic responses in adult offspring. Scientific Reports 8 8077. (https://doi.org/10.1038/s41598-018-26462-w)

Suderman M, McGowan PO, Sasaki A, Huang TC, Hallett MT, Meaney MJ, Turecki G \& Szyf M 2012 Conserved epigenetic sensitivity to early life experience in the rat and human hippocampus. PNAS 109 17266-17272. (https://doi.org/10.1073/pnas.1121260109)

Tollenaar MS, Beijers R, Jansen J, Riksen-Walraven JM \& de Weerth C 2011 Maternal prenatal stress and cortisol reactivity to stressors in human infants. Stress 14 53-65. (https://doi.org/10.3109/10253890.2 010.499485)

Tyrka AR, Price LH, Marsit C, Walters OC \& Carpenter LL 2012 Childhood adversity and epigenetic modulation of the leukocyte glucocorticoid receptor: preliminary findings in healthy adults. PLoS One 7 e30148. (https://doi.org/10.1371/journal.pone.0030148)

Ulrich-Lai YM \& Herman JP 2009 Neural regulation of endocrine and autonomic stress responses. Nature Reviews Neuroscience 10 397-409. (https://doi.org/10.1038/nrn2647)

van Dongen J, Nivard MG, Willemsen G, Hottenga JJ, Helmer Q, Dolan CV, Ehli EA, Davies GE, van Iterson M, Breeze CE, et al. 2016 Genetic and environmental influences interact with age and sex in shaping the human methylome. Nature Communications 711115. (https://doi.org/10.1038/ncomms11115)

Vedhara K, Metcalfe C, Brant H, Crown A, Northstone K, Dawe K, Lightman S \& Smith GD 2012 Maternal mood and neuroendocrine programming: effects of time of exposure and sex. Journal of Neuroendocrinology 24 999-1011. (https://doi.org/10.1111/j.13652826.2012.02309.x)

Veenendaal MV, Painter RC, de Rooij SR, Bossuyt PM, van der Post JA, Gluckman PD, Hanson MA \& Roseboom TJ 2013 Transgenerational effects of prenatal exposure to the 1944-45 Dutch famine. BJOG 120 548-553. (https://doi.org/10.1111/1471-0528.12136)

Walder DJ, Laplante DP, Sousa-Pires A, Veru F, Brunet A \& King S 2014 Prenatal maternal stress predicts autism traits in $61 / 2$ year-old children: project ice storm. Psychiatry Research 219 353-360. (https://doi. org/10.1016/j.psychres.2014.04.034)

Weaver IC, Cervoni N, Champagne FA, D’Alessio AC, Sharma S, Seckl JR Dymov S, Szyf M \& Meaney MJ 2004 Epigenetic programming by maternal behavior. Nature Neuroscience 7 847-854. (https://doi. org/10.1038/nn1276)

Wolford E, Lahti-Pulkkinen M, Girchenko P, Lipsanen J, Tuovinen S, Lahti J, Heinonen K, Hamalainen E, Kajantie E, Pesonen AK, et al. 2019 Associations of antenatal glucocorticoid exposure with mental health in children. Psychological Medicine 1-11. (https://doi org/10.1017/S0033291718004129)

Wu Y, Patchev AV, Daniel G, Almeida OF \& Spengler D 2014 Early-life stress reduces DNA methylation of the Pomc gene in male mice. Endocrinology 155 1751-1762. (https://doi.org/10.1210/en.2013-1868)

Yehuda R, Daskalakis NP, Lehrner A, Desarnaud F, Bader HN, Makotkine I, Flory JD, Bierer LM \& Meaney MJ 2014 Influences of maternal and paternal PTSD on epigenetic regulation of the glucocorticoid receptor gene in Holocaust survivor offspring. American Journal of Psychiatry 171 872-880. (https://doi.org/10.1176/appi.ajp.2014.13121571)

Yeshurun S, Rogers J, Short AK, Renoir T, Pang TY \& Hannan AJ 2017 Elevated paternal glucocorticoid exposure modifies memory retention in female offspring. Psychoneuroendocrinology 83 9-18. (https://doi. org/10.1016/j.psyneuen.2017.05.014)

Youngson NA \& Whitelaw E 2008 Transgenerational epigenetic effects Annual Review of Genomics and Human Genetics 9 233-257. (https:// doi.org/10.1146/annurev.genom.9.081307.164445)

Received in final form 22 March 2019

Accepted 27 March 2019

Accepted Preprint published online 27 March 2019 https://joe.bioscientifica.com https://doi.org/10.1530/JOE-19-0057 (c) 2019 Society for Endocrinology Published by Bioscientifica Ltd. Printed in Great Britain 